\title{
Sex and Disease-Related Alterations of Anterior Insula Functional Connectivity in Chronic Abdominal Pain
}

\author{
Jui-Yang Hong, ${ }^{1,5,8}$ Lisa A. Kilpatrick, ${ }^{1,2,3,5}$ Jennifer S. Labus, ${ }^{1,2,3,4,5}$ Arpana Gupta, ${ }^{1,3,5}$ David Katibian, ${ }^{1}$ \\ (Dody Ashe-McNalley, ${ }^{1,2,3,5}$ Jean Stains, ${ }^{1,3,5}$ Nuwanthi Heendeniya, ${ }^{1,3,5}$ Suzanne R. Smith, ${ }^{1,3,5}$ Kirsten Tillisch, ${ }^{1,2,3,5}$ \\ Bruce Naliboff, $1,2,3,4,5$ and $\odot$ Emeran A. Mayer ${ }^{1,2,3,4,5,6,7}$ \\ ${ }^{1}$ Gail and Gerald Oppenheimer Family Center for Neurobiology of Stress, ${ }^{2}$ Pain and Interoception Imaging Network, ${ }^{3}$ Department of Medicine, ${ }^{4}$ Brain \\ Research Institute, ${ }^{5}$ Division of Digestive Diseases, ${ }^{6}$ Department of Psychiatry, ${ }^{7}$ Ahmanson Lovelace Brain Mapping Center, David Geffen School of \\ Medicine, and ${ }^{8}$ Department of Bioengineering, University of California, Los Angeles, Los Angeles, California 90095
}

Resting-state functional magnetic resonance imaging has been used to investigate intrinsic brain connectivity in healthy subjects and patients with chronic pain. Sex-related differences in the frequency power distribution within the human insula (INS), a brain region involved in the integration of interoceptive, affective, and cognitive influences, have been reported. Here we aimed to test sex and disease-related alterations in the intrinsic functional connectivity of the dorsal anterior INS. The anterior INS is engaged during goaldirected tasks and modulates the default mode and executive control networks. By comparing functional connectivity of the dorsal anterior INS in age-matched female and male healthy subjects and patients with irritable bowel syndrome (IBS), a common chronic abdominal pain condition, we show evidence for sex and disease-related alterations in the functional connectivity of this region: (1) male patients compared with female patients had increased positive connectivity of the dorsal anterior INS bilaterally with the medial prefrontal cortex (PFC) and dorsal posterior INS; (2) female patients compared with male patients had greater negative connectivity of the left dorsal anterior INS with the left precuneus; (3) disease-related differences in the connectivity between the bilateral dorsal anterior INS and the dorsal medial PFC were observed in female subjects; and (4) clinical characteristics were significantly correlated to the insular connectivity with the dorsal medial PFC in male IBS subjects and with the precuneus in female IBS subjects. These findings are consistent with the INS playing an important role in modulating the intrinsic functional connectivity of major networks in the resting brain and show that this role is influenced by sex and diagnosis.

Key words: fMRI; IBS; insula; pain; sex difference

\section{Introduction}

Resting-state functional magnetic resonance imaging (fMRI) has been used increasingly to examine intrinsic brain connectivity in both healthy subjects (Spreng et al., 2013; Wang et al., 2014) and various disease populations (Mainero et al., 2011; Woodward et al., 2012). Alterations in the connectivity of regions comprising major intrinsic brain networks at rest have been reported in patients with chronic pain disorders, including fibromyalgia (Napadow et al., 2010), chronic back pain (Kong et al., 2013), and headache (Xue et al., 2012; Qiu et al., 2013). Irritable bowel syndrome (IBS), the most common visceral pain disorder, is charac-

Received April 10, 2014; revised Aug. 27, 2014; accepted Sept. 1, 2014.

Author contributions: J.-Y.H., L.A.K., J.S.L., and E.A.M. designed research;J.-Y.H., J.S., N.H., and S.R.S. performed research; L.A.K., J.S.L., C.A.-M., K.T., B.N., and E.A.M. contributed unpublished reagents/analytic tools; J.-Y.H. analyzed data; J.-Y.H., L.A.K., J.S.L., A.G., D.K., and E.A.M. wrote the paper.

This work was supported by National Institutes of Health Grants R01 DK048351, P50 DK064539, U01 DK082370, P30 DK041301, and R01 AT007137. Pilot scanning was provided by University of California, Los Angeles AhmansonLovelace Brain Mapping Center.

The authors declare no competing financial interests

Correspondence should be addressed to Dr. Emeran A. Mayer, Gail and Gerald Oppenheimer Family Center for Neurobiology of Stress, 10833 Le Conte Avenue, CHS 42-210 MC 737818, Los Angeles, CA 90095-7378. E-mail: emayer@ucla.edu.

DOI:10.1523/JNEUROSCI.1683-14.2014

Copyright $\odot 2014$ the authors $\quad 0270-6474 / 14 / 3414252-08 \$ 15.00 / 0$ terized by chronically recurrent abdominal pain associated with changes in bowel habits (Drossman, 2006). Like many other chronic pain syndromes, IBS is more prevalent in women (Adeyemo and Chang, 2008; Chang, 2011). Disease-related differences in the activity and responses of several brain regions, including the insula (INS), anterior cingulate cortex, and prefrontal cortex (PFC), have consistently been observed in IBS subjects, using resting-state and task-based fMRI (Rapps et al., 2008; Mayer et al., 2009; Tillisch et al., 2011; Hong et al., 2013). Sexrelated differences in both healthy controls (HCs) and IBS subjects have been found in numerous studies, including task-based (Labus et al., 2008, 2013), morphometric (Luders and Toga, 2010; Jiang et al., 2013; Ingalhalikar et al., 2014), and resting-state imaging studies (Allen et al., 2011; Filippi et al., 2013; Hong et al., 2013). We reported recently sex and disease-related differences in spontaneous blood oxygen level-dependent (BOLD) signal oscillations in IBS, with female patients showing greater highfrequency power in the INS compared with female HCs and male IBS subjects (Hong et al., 2013).

Cognitive factors, including selective attention and pain prediction, play an important role in the subjective experience of pain in both HCs and chronic pain patients (Dunckley et al., 2007; Wiech and Tracey, 2013), and sex-related differences in 
these cognitive factors have been reported (Straube et al., 2009; Popescu et al., 2010). Engagement of dorsal anterior INS during pain perception (Lutz et al., 2013), executive control and attention processing (Dosenbach et al., 2007; Chang et al., 2013), and prediction (Preuschoff et al., 2008) have been observed consistently. In the current study, we aimed to characterize sex and disease-related differences in resting-state functional connectivity of dorsal anterior INS in age-matched HCs and IBS patients. Specifically, we wanted to test the following hypotheses: (1) disease-related differences exist in the way that the dorsal anterior INS is functionally connected to other brain regions (e.g., PFC); (2) sex-related differences exist in the functional connectivity of the dorsal anterior INS in both HCs and IBS subjects; and (3) the functional connectivity differences are correlated with clinical characteristics.

\section{Materials and Methods}

Subjects. Ninety-six age-matched and right-handed subjects were recruited through the University of California, Los Angeles (UCLA) Digestive Diseases Clinic and advertisements. The sample included 24 male HCs (mean \pm SD age, $34.33 \pm 11.19$ years), 24 female HCs (mean \pm SD age, $30.67 \pm 9.9$ years), 24 male IBS subjects (mean \pm SD age, $34.71 \pm$ 10.38 years), and 24 female IBS subjects (mean \pm SD age, $33.58 \pm 9.74$ years). Fifty-two subjects have been used in a previous study from our group (Hong et al., 2013). All procedures were approved by the UCLA Medical Institutional Review Board, and all subjects provided informed consent. Exclusion criteria included substance abuse, pregnancy, tobacco dependence, abdominal surgery, and psychiatric illness as determined by the Mini International Neuropsychiatric Interview (Sheehan et al., 1998). Diagnosis of IBS was made by a gastroenterologist or nurse practitioner with expertise in functional gastrointestinal (GI) disorders based on the Rome III symptom criteria during a clinical assessment (Drossman, 2006). The diagnostic criteria included recurrent abdominal pain or discomfort associated with two or more of the following: (1) pain/discomfort is relieved/improved by defecation; (2) the onset of pain/discomfort is related to a change in frequency of stool; and (3) the onset of pain/discomfort is related to a change in the form (appearance) of stool.

Materials. Questionnaires were completed before scanning to determine GI symptom type, duration of symptoms, severity, and abdominal sensation during the past week [UCLA bowel symptom questionnaire (BSQ); Chang et al., 2001], levels of anxiety and depression [hospital anxiety depression scale (HAD); Mykletun et al., 2001], GI symptomspecific perception associated with prediction, fear, and worry [visceral sensitivity index (VSI); Labus et al., 2004, 2007], and intensity of GI symptoms over the past $24 \mathrm{~h}$ with using the Gracely pain scale (Heft et al., 1980).

Image data acquisition. All resting-state images were acquired with subjects resting with eyes closed during a $10 \mathrm{~min}$ scan in a Siemens 3 Tesla Trio scanner with the following: echo planar sequence; repetition time (TR), $2000 \mathrm{~ms}$; echo time (TE), $28 \mathrm{~ms}$; flip angle, $77^{\circ}$; slice thickness, 4 $\mathrm{mm} ; 40$ slices obtained with whole-brain coverage. High-resolution structural images were collected with the following: standard T1weighted magnetization-prepared rapid acquisition gradient echo (MP-RAGE); TR, 2200 ms; TE, 3.26 ms; slice thickness, 1 mm; 176 slices; $256 \times 256$ voxel matrices; and $1.0 \times 1.0 \times 1.0 \mathrm{~mm}$ voxel size.

Resting-state fMRI image preprocessing. Resting-state image preprocessing was performed using Statistical Parametric Mapping 8 (SPM8) software (Wellcome Department of Cognitive Neurology, London, UK). The first three volumes were removed to allow for scanner stabilization. Images were transformed from DICOM into NifTI format, slice-time corrected, spatially normalized to the MNI template with the MP-RAGE scan, and resampled to a voxel size of $2 \times 2 \times 2 \mathrm{~mm}$.

Resting-state fMRI seed-to-voxel analysis. Preprocessed and normalized functional images were imported into the CONN-fMRI functional connectivity toolbox version 13 (Whitfield-Gabrieli and NietoCastanon, 2012; http://www.nitrc.org/projects/conn) for additional pre- processing and for seed-to-voxel connectivity analysis. A componentbased noise-correction method, CompCor, was used to remove nonneural noises without regressing out the global signal to increase sensitivity and specificity of connectivity analysis (Behzadi et al., 2007; Whitfield-Gabrieli and Nieto-Castanon, 2012). Three-dimensional confounds for both white matter and CSF, as well as six realignment parameters and first-order temporal derivatives of motion, were removed using regression. Resting-state images then were bandpass filtered between 0.008 and $0.08 \mathrm{~Hz}$ in the CONN toolbox. Bilateral dorsal anterior INSs were selected as the regions of interests (ROIs) based on previous research (Deen et al., 2011; Chang et al., 2013). Dr. J.-Y. Hong delineated the left and right dorsal anterior INS on the Destrieux Atlas template (Fischl et al., 2004) by following the boundaries of the anterior limiting sulcus and short insular sulcus and by using the coordinate $z=-1$ in MNI space (Naidich et al., 2004; Craig, 2009; Kurth et al., 2010). Connectivity correlation coefficients representing the association between average BOLD time series across all voxels within the left and right dorsal anterior INS, and every voxel in the brain was calculated using a general linear model. Each ROI Fisher's $r$ to $z$ transformed bivariate correlation maps were smoothed with a $4 \mathrm{~mm}$ isotropic Gaussian kernel and submitted into group-level analyses implemented in SPM8.

Conjunction analysis. For right and left dorsal anterior INS, a secondlevel random-effects full factorial model was specified with group (male IBS, female IBS, male HCs, and female HCs) as a factor and age, anxiety, and depression scores as covariates. A cerebral cortex explicit mask was applied. To examine the functional connectivity patterns (positive and negative) of the dorsal anterior INS among all four groups, conjunction null tests were performed in SPM8 (Friston et al., 2005). After applying a voxelwise threshold $p$ value of 0.005 , significance was considered at a cluster threshold of $p<0.05$ corrected for multiple comparisons using familywise error (FWE).

ANOVA. For second-level group comparison, a voxelwise one-way ANOVA test was performed to determine differences among the four groups (male IBS, female IBS, male HCs, and female HCs) in the left and right dorsal anterior INS correlation maps. To account for multiple comparisons, results were corrected by performing Monte Carlo simulation implemented in AlphaSim (http://afni.nimh.nih.gov/afni/doc/manual/ AlphaSim; Song et al., 2011) at 10,000 iterations, cluster connection radius of $3.46 \mathrm{~mm}$, and FWHM of $4 \mathrm{~mm}$. The simulation demonstrated that clusters with a voxel threshold of $p<0.005$ with a contiguous cluster size of $>29$ voxels within a brain mask had a corrected $p$ value $<0.05$. To further describe the significant group differences detected in SPM8, we extracted the connectivity correlation coefficient ( $z$ value) averaged over the voxels within each significant cluster and performed post hoc tests in SPSS version 19 software with four different contrasts (male HCs vs female HCs, male HCs vs male IBS, female HCs vs female IBS, and male IBS vs female IBS). A sex and disease interaction analysis was also performed. False-discovery rate (FDR) correction at $p<0.05$ (Benjamini and Hochberg, 2000; Benjamini et al., 2006) was applied to correct for multiple comparisons. We also plotted the mean of the $z$ values for each group.

Clinical characteristics analysis. ANOVA with post hoc comparisons were used to test for differences in age, VSI, and HAD anxiety and depression. All $p$ values were corrected for multiple comparisons using FDR correction at 5\% (Benjamini and Hochberg, 2000; Benjamini et al., 2006). Independent-samples $t$ tests were performed to examine BSQ measures between male and female IBS subjects.

Correlation analysis. To examine the possible associations between clinical characteristics and altered functional connectivity, we performed correlation analyses in SPSS software. Averaged $z$ values within the significant clusters were correlated with VSI, BSQ, and past $24 \mathrm{~h}$ symptom intensity for the IBS groups separately. Significant correlations were defined at $p<0.05$.

\section{Results}

\section{Clinical characteristics}

The clinical data are summarized in Table 1. Anxiety and depression symptom scores were greater in male IBS patients compared with male HCs (anxiety, $p=0.033$; depression, $p=0.021$ ) and in 
Table 1. Clinical characteristics

\begin{tabular}{|c|c|c|c|c|c|c|c|c|c|c|c|c|c|c|}
\hline & \multicolumn{3}{|c|}{$\mathrm{HCM}$} & \multicolumn{3}{|c|}{$\mathrm{HCF}$} & \multicolumn{3}{|c|}{ IBSM } & \multicolumn{3}{|c|}{ IBSF } & \multirow[b]{2}{*}{$F / t$} & \multirow[b]{2}{*}{ Significance } \\
\hline & $n$ & Mean & SD & $n$ & Mean & SD & $n$ & Mean & SD & $n$ & Mean & SD & & \\
\hline Age (years) & 24 & 34.33 & 11.19 & 24 & 30.67 & 9.9 & 24 & 34.71 & 10.38 & 24 & 33.58 & 9.74 & 0.76 & 0.52 \\
\hline Anxiety symptoms ${ }^{1}$ & 24 & 3 & 2.7 & 24 & 1.91 & 1.77 & 24 & 5.83 & 4.88 & 24 & 7.96 & 5.55 & 11.13 & $<0.001$ \\
\hline Depression symptoms ${ }^{1}$ & 24 & 1.38 & 1.53 & 24 & 0.46 & 0.78 & 24 & 3.17 & 2.88 & 24 & 3.79 & 3.37 & 10.15 & $<0.001$ \\
\hline $\mathrm{VSI}^{2}$ & 23 & 3.39 & 4.46 & 22 & 2.14 & 4.64 & 24 & 32.08 & 15.72 & 24 & 43.04 & 16.67 & 68 & $<0.001$ \\
\hline Overall bowel symptoms ${ }^{3}$ & & & & & & & 24 & 9.96 & 4.23 & 24 & 8.83 & 4.8 & 0.97 & 0.39 \\
\hline Abdominal pain 4 & & & & & & & 24 & 9.17 & 4.48 & 24 & 8.75 & 4.81 & 0.41 & 0.76 \\
\hline Abdominal discomfort ${ }^{5}$ & & & & & & & 24 & 9.79 & 5.18 & 24 & 11.21 & 5.89 & 0.89 & 0.38 \\
\hline Duration of symptoms ${ }^{6}$ & & & & & & & 24 & 13 & 9.31 & 22 & 13.14 & 9.86 & 0.05 & 0.96 \\
\hline Symptom intensity ${ }^{7}$ & & & & & & & 15 & 5.67 & 4.91 & 19 & 7.95 & 4.7 & 1.38 & 0.18 \\
\hline
\end{tabular}

$F / t$, Main effect of group from ANOVA and $t$ test for four and two group comparisons, respectively. Statistically significant, $p<0.05 . M$, male; $F$, female.

${ }^{1} \mathrm{HAD}$ (Mykletun et al., 2001).

${ }^{2}$ VSI (Labus et al., 2004, 2007).

BSQ: Chang et al. (2001).

${ }^{3} \mathrm{BSQ}$ overall symptoms in the past week $(0-20)$.

${ }^{4} \mathrm{BSQ}$ abdominal pain in the past week $(0-20)$.

${ }^{5} \mathrm{BSQ}$ discomfort in the past week $(0-20)$.

${ }^{6} \mathrm{BSQ}$ duration in years, derived from the onset of symptoms.

${ }^{7}$ Intensity of Gl symptoms over the past $24 \mathrm{~h}(0-20)$.

female IBS patients compared with female HCs (anxiety, $p<$ 0.001 ; depression, $p<0.001$ ). Higher anxiety and depression symptom scores were observed in female patients compared with male patients, although the differences did not reach statistical significance. Male and female patients had significantly higher VSI scores than male and female HCs, respectively $(p<0.001$ and $p<$ $0.001)$. In addition, female IBS subjects showed significantly higher VSI scores than male IBS subjects $(p=0.003)$. There was no significant difference in IBS-related symptom scores (i.e., BSQ) between male and female IBS subjects. Intensity of GI symptoms over the past $24 \mathrm{~h}$ was higher in female IBS subjects compared with male IBS subjects, but it did not reach significance $(p=0.18)$. In the study, $87.5 \%$ women were in the premenopausal stage ( 22 female HCs and 20 female IBS subjects who were well balanced in terms of luteal and follicular phases during scanning).

\section{Connectivity of the dorsal anterior INS among all groups}

We first investigated the functional connectivity patterns of the dorsal anterior INS shared by all subjects (IBS plus HCs). Significant results from the whole-brain connectivity analyses with the dorsal anterior INS seeds are shown in Figure 1. The bilateral dorsal anterior INS showed positive functional connectivity with widespread brain regions, including the cingulate subregions (mid and anterior cingulate cortex), INS, supramarginal gyrus, and somatosensory (thalamus, putamen), motor (supplementary motor area, precentral gyrus), frontotemporal (inferior frontal gyrus, rolandic operculum, middle frontal gyrus, superior temporal gyrus), and affective (amygdala) regions (Fig. 1a,b). We also observed the bilateral dorsal anterior INS to be negatively connected to the bilateral precuneus and angular gyrus (Fig. 1c,d).

\section{Group differences in dorsal anterior INS connectivity}

As shown in Table 2, significant group differences were identified for several regions that were functionally connected to the dorsal anterior INS, including the bilateral dorsal medial PFC [Brodmann area 9 (BA 9)], medial PFC (BA 10), left dorsal posterior INS, and left precuneus. Post hoc tests were performed to examine between-group functional connectivity differences. Male HCs and male IBS subjects showed significantly greater positive connectivity between bilateral dorsal anterior INS and left dorsal posterior INS compared with female HCs and female IBS sub- jects, respectively (Figs. 2, 3; Table 2). Similarly, male HCs and male IBS subjects showed greater right dorsal anterior INS connectivity to the right medial PFC than female HCs and IBS subjects, respectively. This was attributable to the right dorsal anterior INS being positively connected to the right medial PFC in male subjects but negatively connected in female subjects (Fig. 3; Table 2). Disease-related differences in the connectivity of the left dorsal anterior INS with the left medial PFC (BA 10) and the left dorsal medial PFC (BA 8/9) were observed within the female subjects (Fig. 2; Table 2). Although negative connectivity between the dorsal anterior INS and these PFC regions were observed in female HCs and female IBS subjects, female IBS subjects showed greater negative connectivity than both female HCs and male IBS subjects (Figs. 2, 3; Table 2). Similarly, the left dorsal anterior INS was negatively connected to the left precuneus in all subjects, but female IBS subjects showed significantly greater negative connectivity compared with female HCs and male IBS subjects (Fig. 2; Table 2). Sex and disease interactions were observed in the connectivity of the left dorsal anterior INS with the left medial PFC $(p=0.032)$ and precuneus $(p=0.015)$.

\section{Correlations of dorsal anterior INS functional connectivity with clinical characteristics}

We correlated functional connectivity measures with symptom scores for male and female IBS subjects separately. In male IBS subjects, VSI significantly correlated with the connectivity between the bilateral dorsal anterior INS and the dorsal medial PFC (left, $r=0.442, p=0.031$; right, $r=0.405, p=0.05$ ) and between the left dorsal anterior INS and the left medial PFC $(r=0.41, p=$ $0.047)$. In female IBS subjects, ratings of past $24 \mathrm{~h}$ symptom intensity significantly correlated with the connectivity between the left dorsal anterior INS and the precuneus $(r=0.597, p=0.007)$ and between the bilateral dorsal anterior INS and the dorsal medial PFC (left, $r=$ $0.474, p=0.04$; right, $r=0.466, p=0.044$ ).

\section{Discussion}

Using resting-state functional connectivity analysis, we investigated the disease and sex-related differences in the connectivity of the dorsal anterior INS in 96 male and female HCs and IBS subjects. The main findings of this study were as follows. (1) Among all subjects, the dorsal anterior INS showed positively functional 


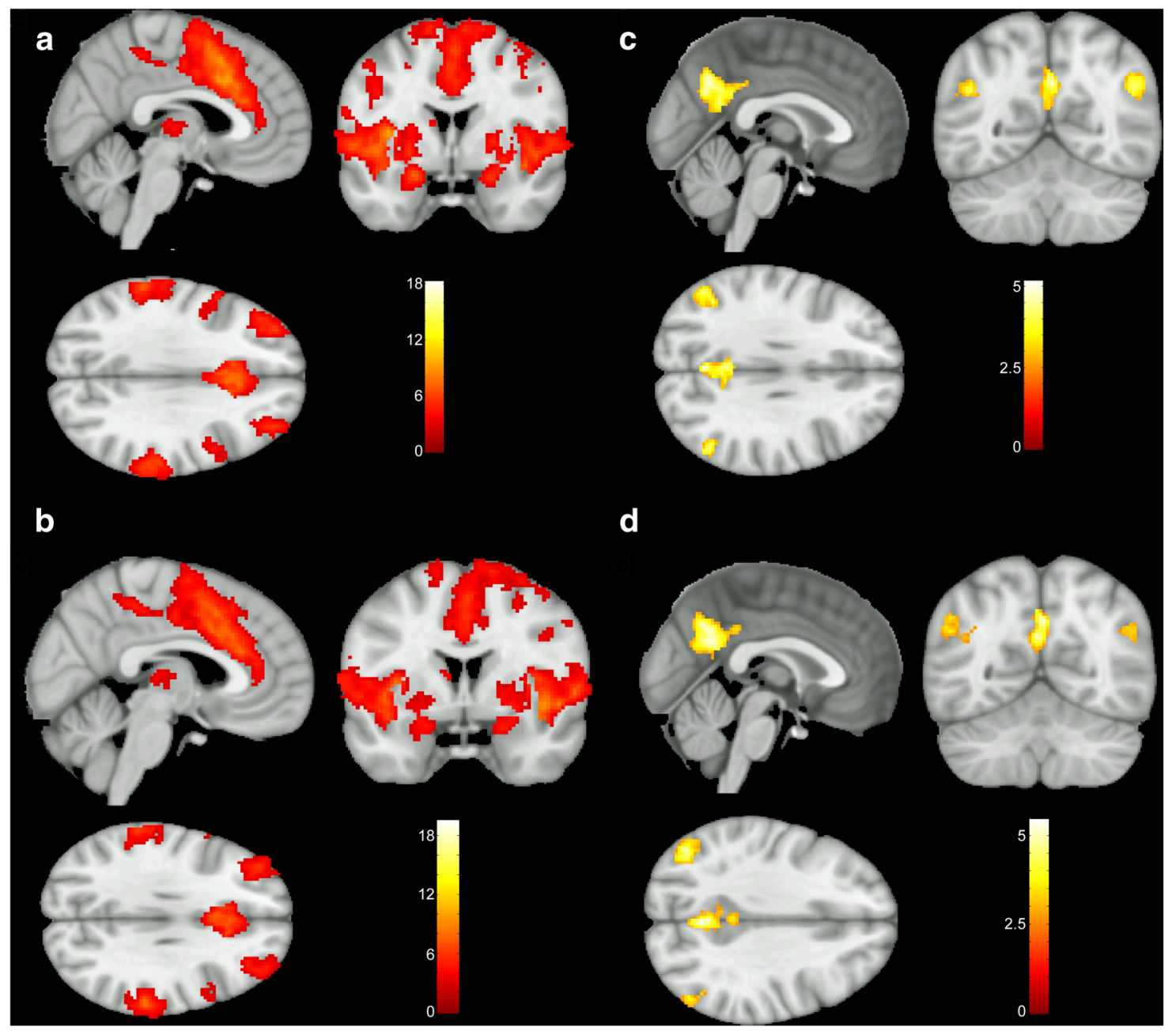

Figure 1. Significant clusters connected to the dorsal anterior INS among all subjects. Regions showed positive functional connectivity to the left dorsal anterior INS (a) and the right dorsal anterior INS (b). Regions were negatively connected to the left dorsal anterior INS (c) and the right dorsal anterior INS (d). Images were thresholded at a voxelwise $p$ value of 0.005 and clusterwise corrected for multiple comparisons using FWE correction at a $p$ value $<0.05$.

Table 2. Significant differences (ANOVA) of the functional connectivity with the dorsal anterior INS among male and female HCs and IBS subjects

\begin{tabular}{|c|c|c|c|c|c|c|c|}
\hline & Peak Fvalue & Z & Voxels & $x$ & $y$ & $z$ & Post hoc $\left(P_{\text {corr }}\right)$ \\
\hline \multicolumn{8}{|l|}{ L_dalNS with } \\
\hline L_mPFC (BA 10) & 11.31 & 4.58 & 108 & -8 & 52 & 10 & $\operatorname{IBSM}>\operatorname{IBSF}(<0.001) ; \mathrm{HCF}>\operatorname{IBSF}(0.018)$ \\
\hline L_dpINS & 8.08 & 3.77 & 61 & -40 & -10 & 8 & $\operatorname{IBSM}>\operatorname{IBSF}(<0.001) ; \mathrm{HCM}>\mathrm{HCF}(0.03)$ \\
\hline L_dmPFC (BA 8/9) & 7.7 & 3.66 & 52 & -16 & 34 & 54 & $\operatorname{IBSM}>\operatorname{IBSF}(<0.001) ; \mathrm{HCM}>\operatorname{HCF}(0.008) ; \mathrm{HCF}>\operatorname{IBSF}(0.025)$ \\
\hline \multirow[t]{2}{*}{ L_precuneus } & 6.82 & 3.39 & 32 & -4 & -44 & 40 & $\operatorname{IBSM}>\operatorname{IBSF}(<0.001) ; \mathrm{HCF}>\operatorname{IBSF}(0.006)$ \\
\hline & 7.42 & 3.58 & 30 & -14 & -54 & 26 & \\
\hline \multicolumn{8}{|l|}{ R_dalNS with } \\
\hline R_mPFC (BA 10) & 9.25 & 4.09 & 78 & 4 & 54 & 12 & IBSM $>\operatorname{IBSF}(<0.001) ; \mathrm{HCM}>\mathrm{HCF}(0.007)$ \\
\hline L_dpINS & 9.15 & 4.06 & 60 & -46 & -12 & 12 & IBSM $>\operatorname{IBSF}(<0.001) ; \mathrm{HCM}>\mathrm{HCF}(<0.001)$ \\
\hline$R \_d m P F C(B A 9)$ & 7.42 & 3.58 & 54 & 20 & 48 & 40 & IBSM $>$ IBSF $(0.006) ; \mathrm{HCF}>\operatorname{IBSF}(0.006)$ \\
\hline
\end{tabular}

MNI coordinates $(x, y, z)$ for peak voxel; $M$, male; $F$, female; L, left; $R$, right; daINS, dorsal anterior INS; dpINS, dorsal posterior INS; dmPFC, dorsal medial PFC; $m P F C$, medial PFC; $P_{\text {corr }}$ statistical significance at $p<0.05$, corrected.

connectivity with the entire INS, as well as with frontal, sensorimotor, and affective regions and with cingulate subregions. (2) Disease-related differences in the connectivity were seen in female subjects and included greater negative dorsal anterior INS connectivity with the left precuneus and frontal regions. (3) Sexrelated differences in the dorsal anterior INS connectivity to the medial PFC and dorsal medial PFC were observed in both HCs and IBS subjects, and these sex-related differences were magnified in IBS subjects. (4) Clinical measures were correlated with the connectivity between the dorsal anterior INS and the dorsal medial PFC in male IBS patients, as well as between the dorsal anterior INS and the precuneus in female IBS subjects. These findings in a chronic visceral pain population for the first time demonstrate differential intrinsic brain connectivity of the dorsal anterior INS depending on sex and diagnosis.

\section{Functional connectivity of large-scale networks among} all groups

Studies have used resting-state functional connectivity networks to characterize interactions of brain regions associated with spe- 
a

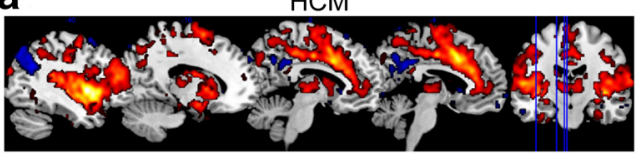

$\mathrm{HCF}$

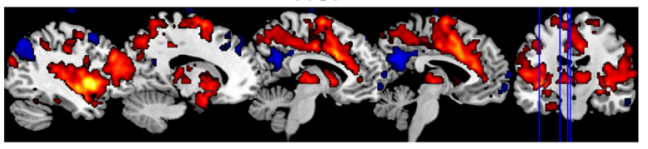

IBSF

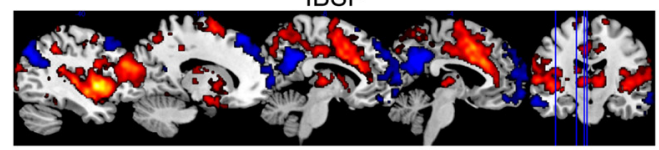

IBSM

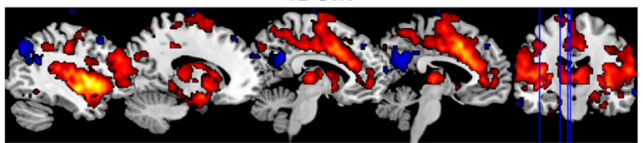

b

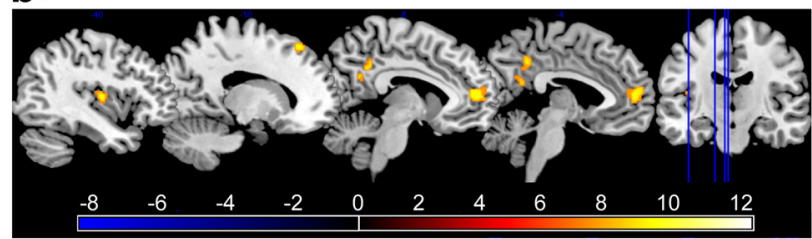

C

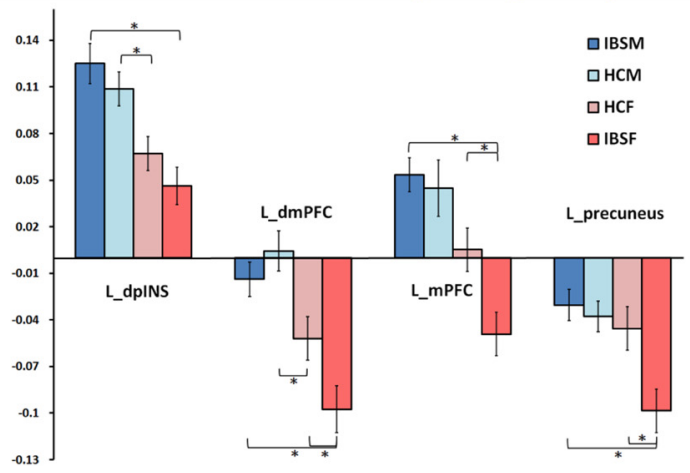

Figure 2. Group differences in functional connectivity of the left dorsal anterior INS. $\boldsymbol{a}$, Single-group connectivity maps of the left dorsal anterior INS. For display purposes only, all statistical results, thresholding at $p<0.005$ uncorrected and cluster $>29$ voxels, were overlapped on a MRIcron ch2better template. Red, Positive connectivity; blue, negative connectivity. $\boldsymbol{b}$, Regions showed significant functional connectivity differences between groups ( $p<0.05$, corrected). $c$, Graph showed mean Z scores of significant regions connected with the left dorsal anterior INS for each group. * indicates significant difference after controlling for age, anxiety, and depression, $p<0.05$, corrected. Error bars reflect SE. dmPFC, dorsal medial PFC; dpINS, dorsal posterior INS; HCF, HC females; HCM, HC males; IBSF, IBS female patients; IBSM, IBS male patients; L, left; mPFC, medial PFC.

a
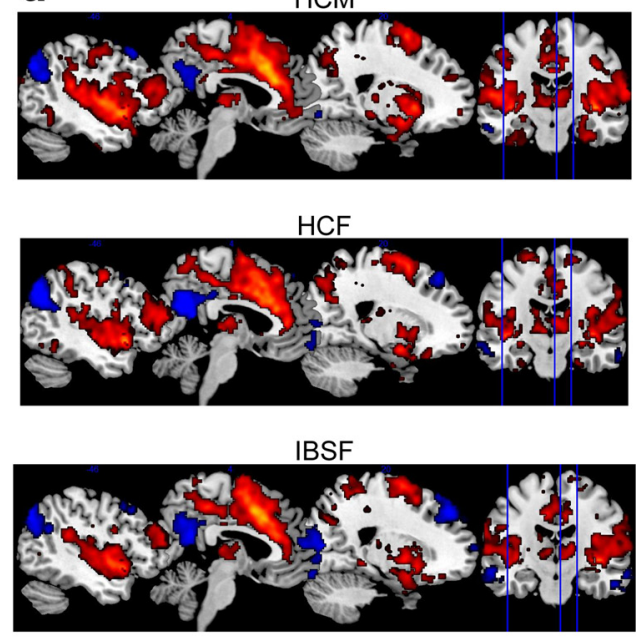

IBSM

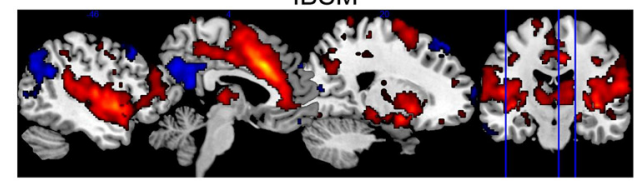

b

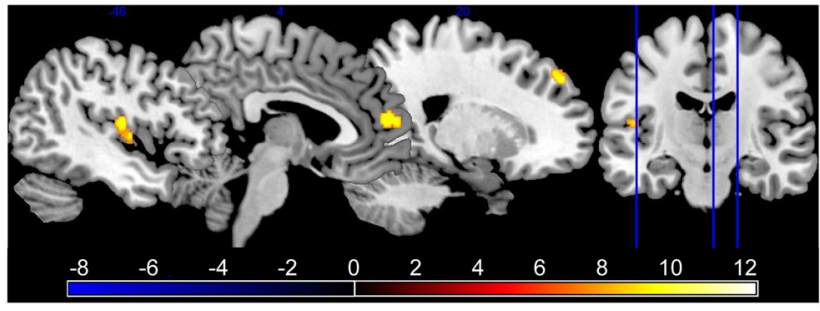

\section{c}

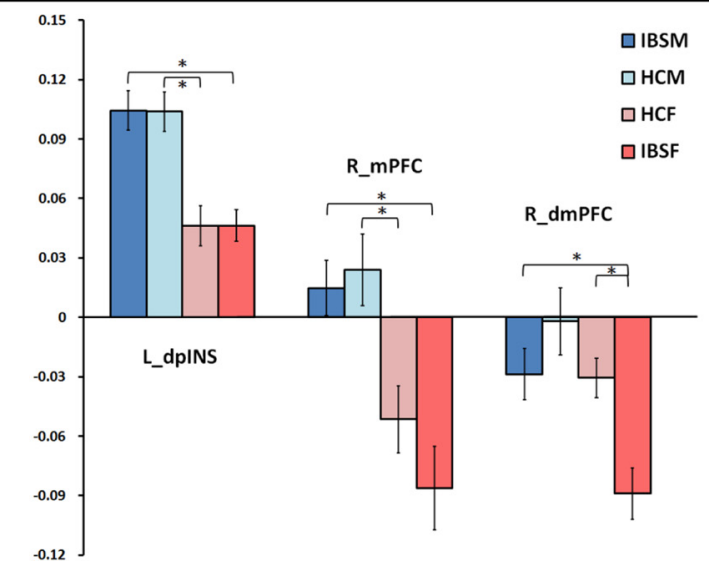

Figure 3. Group differences in functional connectivity of the right dorsal anterior INS. $\boldsymbol{a}$, Single-group positive and negative connectivity maps of the right dorsal anterior INS (all statistical results were overlapped on a MRIcron ch2better template). $\boldsymbol{b}$, Regions showed significant functional connectivity differences between groups ( $p<0.05$, corrected). $\boldsymbol{c}$, Graph showed average $Z$ scores of significant regions connected with the right dorsal anterior INS for each group. * indicates significant difference after controlling for age, anxiety, and depression, $p<0.05$, corrected for multiple comparison. dmPFC, dorsal medial PFC; dpINS, dorsal posterior INS; HCF, HC females; HCM, HC males; IBSF, IBS female patients; IBSM, IBS male patients; L, left; mPFC, medial PFC; R, right.

cific functions. Several robust resting-state networks have been revealed, including the default mode network (DMN; Buckner et al., 2008), the salience network (Seeley et al., 2007), and the executive control network (ECN; Dosenbach et al., 2007; Laird et al., 2011; Touroutoglou et al., 2012; Spreng et al., 2013). However, discrepancies in the inclusion of certain brain regions in a particular network still exist between different studies depending on analysis strategies, network definitions, and study samples. Converging evidence from functional imaging studies suggests that the dorsal anterior INS is involved in attention, cognitive control, prediction, and pain perception (Touroutoglou et al., 2012; Chang et al., 2013). In accordance with previous studies (Deen et al., 2011; Moran et al., 2013), we observed in the combined dataset (male plus female; IBS plus HCs) that the dorsal 
anterior INS was positively connected to several task-positive resting-state networks (Di and Biswal, 2014), including the ECN and the salience network. We also observed negative connectivity of the dorsal anterior INS with the precuneus and angular gyrus, both of which are part of the DMN. Our findings of positive and negative functional connectivity of the dorsal anterior INS with regions of different brain networks are similar to previous reports on anticorrelations between task-negative and task-positive networks (Fox et al., 2005). Recently, a triple network model has been proposed in which the anterior INS plays a critical role in switching between the ECN and DMN (Sridharan et al., 2008; Menon and Uddin, 2010). In line with these reports, our findings are consistent with a role for dorsal anterior INS functioning as a major hub mediating the interactions between task-positive and task-negative networks.

\section{Disease-related differences in the functional connectivity}

Altered intrinsic functional connectivity in resting-state networks have been reported in several chronic pain conditions (Baliki et al., 2008; Napadow et al., 2010; Qiu et al., 2013). Given that IBS-related differences in functional brain activity involving the anterior INS have also been reported (Elsenbruch et al., 2010; Hong et al., 2013), we aimed to test the hypothesis that the dorsal anterior INS shows disease-related alterations in functional connectivity. Female IBS patients compared with female HCs displayed greater negative functional connectivity of the dorsal anterior INS with the medial PFC and precuneus, which are key components of the DMN. Napadow et al. (2010) also found greater functional connectivity in female fibromyalgia patients (compared with HCs) between the DMN and regions involved in pain perception, including the dorsal anterior INS. The reason for the difference in the direction of the functional connectivity between the two studies is unclear but may be attributable to differences in study techniques. For example, we used the dorsal anterior INS as a seed and correlated to all voxels within the brain mask, whereas Napadow et al. performed independent component analysis and compared the selected DMN maps. Although $\mathrm{DMN}$ is usually anticorrelated with task-positive networks, heterogeneity of sub-DMN components may exist and be activated or deactivated depending on the task (Leech et al., 2011; Anticevic et al., 2012). Similar to our findings, alterations in the connectivity of the anterior INS have also been reported in subjects with migraine (Xue et al., 2012) and schizophrenia (Moran et al., 2013; Manoliu et al., 2014).

\section{Sex-related differences in the functional connectivity}

A comprehensive resting-state imaging study has suggested that sex-related differences exist in functional connectivity within both the task-positive network and DMN (Biswal et al., 2010). Similarly, in the current study, several sex-related differences in functional connectivity of the dorsal anterior INS with other brain regions were observed.

\section{Intrainsular connectivity}

Male subjects showed greater functional connectivity between the dorsal anterior INS and the dorsal posterior INS compared with females. Because the posterior INS functions as a primary interoceptive representation area receiving inputs from somatosensory and viscerosensory regions (Craig, 2009; Farb et al., 2013), one may speculate that male subjects exert greater cognitive modulation of primary sensory information than females.
Connectivity with precuneus

Compared with male HCs, female $\mathrm{HCs}$ showed greater negative connectivity between the dorsal anterior INS and the precuneus, and this sex-related difference was magnified in IBS subjects. Failures of downregulation within the precuneus and shifting away from the DMN in response to pain stimuli have been observed in female IBS subjects (Hall et al., 2010). One may speculate that the negative connectivity of the precuneus with the dorsal anterior INS is related to modulation of the DMN by the INS in female subjects and is enhanced in female IBS patients.

Connectivity between the dorsal anterior INS and the medial PFC Sex-related differences for functional connectivity between the dorsal anterior INS and the medial PFC were observed, with males showing positive connectivity and females showing negative connectivity. The medial PFC plays roles in social cognition, self-relevance, and emotion regulation (Etkin et al., 2011; Menon, 2011) and can engage in either the DMN or ECN depending on the condition-oriented function (Daniels et al., 2010). A recent study proposed that the anterior INS may play a role in this condition-dependent switching and modulation of function (Menon and Uddin, 2010). Our results suggest that this modulation mechanism can be influenced by sex even during the resting state: the medial PFC appears to be more engaged in cognitive function for males given the positive connectivity with the dorsal anterior INS, whereas the medial PFC may be more involved in self-referential mental activity for females, especially female patients, given the negative connectivity with the dorsal anterior INS. Similarly, female subjects with temporomandibular disorder showed strong correlations between medial PFC to precuneus functional connectivity and pain rumination (Kucyi et al., 2014). Although sex hormone levels were not determined in the current study, $87.5 \%$ of female subjects were in the premenopausal state, and female groups were well balanced in terms of menstrual cycle phase in which they were studied. Thus, we feel that a confounding effect of sex hormone levels is unlikely.

\section{Symptoms correlation with dorsal anterior insular connectivity}

In male IBS patients, higher scores of symptom-specific worries and prediction of negative outcomes was associated with increased functional connectivity between the dorsal anterior INS and the dorsal medial PFC, which are suggested to be involved in cognitive functions such as anticipation, error prediction, probability assessment, and expectation of uncertainty (Lovero et al., 2009; Holtz et al., 2012; Grupe and Nitschke, 2013). For female IBS patients, the functional connectivity between the dorsal anterior INS and the precuneus was positively correlated with the reported intensity of recent GI symptoms. This is consistent with findings of previous studies (Napadow et al., 2010; Loggia et al., 2013) in which chronic pain patients (female-predominant) with greater DMN-INS anticorrelation demonstrated less clinical pain and patients with more positive DMN-INS connectivity demonstrated greater clinical pain. When viewed together, the altered DMN-INS connectivity may play a role in the subjective symptom generation in female chronic pain patients, regardless of the specific diagnosis. However, the positive association between DMN-INS connectivity and pain symptoms needs additional study. Collectively, our results suggest that male IBS subjects recruited the dorsal medial PFC during negatively biased predictions about expected GI symptoms, whereas female IBS subjects engaged regions in the DMN to generate self-awareness of symptoms. To more closely link pain state to the intrinsic brain 
activity during scanning, symptom measurements, such as spontaneous pain scores and cognitive-specific task performances, should be included in future studies.

\section{Conclusions}

The results of this study are consistent with previous reports in healthy subjects and in other disease populations suggesting that the dorsal anterior INS plays an important role in modulating the intrinsic functional connectivity of major networks in the resting brain and that this role is influenced by sex and diagnosis. Sexrelated differences in the connectivity patterns of the dorsal anterior INS suggest that the female brain shows greater resource allocation to interoceptive awareness, whereas the male brain relies more on cognitive function. Because these sex-related differences are enhanced in IBS patients, one may speculate that these mechanisms play a role in the pathophysiology of IBS.

\section{References}

Adeyemo MA, Chang L (2008) New treatments for irritable bowel syndrome in women. Womens Health (Lond Engl) 4:605-622; quiz 623. CrossRef Medline

Allen EA, Erhardt EB, Damaraju E, Gruner W, Segall JM, Silva RF, Havlicek M, Rachakonda S, Fries J, Kalyanam R, Michael AM, Caprihan A, Turner JA, Eichele T, Adelsheim S, Bryan AD, Bustillo J, Clark VP, Feldstein Ewing SW, Filbey F, et al. (2011) A baseline for the multivariate comparison of resting-state networks. Front Syst Neurosci 5:2. CrossRef Medline

Anticevic A, Cole MW, Murray JD, Corlett PR, Wang XJ, Krystal JH (2012) The role of default network deactivation in cognition and disease. Trends Cogn Sci 16:584-592. CrossRef Medline

Baliki MN, Geha PY, Apkarian AV, Chialvo DR (2008) Beyond feeling: chronic pain hurts the brain, disrupting the default-mode network dynamics. J Neurosci 28:1398-1403. CrossRef Medline

Behzadi Y, Restom K, Liau J, Liu TT (2007) A component based noise correction method (CompCor) for BOLD and perfusion based fMRI. Neuroimage 37:90-101. CrossRef Medline

Benjamini Y, Hochberg Y (2000) On the adaptive control of the false discovery rate in multiple testing with independent statistics. J Educ Behav Stat 25:60-83. CrossRef

Benjamini Y, Krieger AM, Yekutieli D (2006) Adaptive linear step-up procedures that control the false discovery rate. Biometrika 93:491-507. CrossRef

Biswal BB, Mennes M, Zuo XN, Gohel S, Kelly C, Smith SM, Beckmann CF, Adelstein JS, Buckner RL, Colcombe S, Dogonowski AM, Ernst M, Fair D, Hampson M, Hoptman MJ, Hyde JS, Kiviniemi VJ, Kötter R, Li SJ, Lin CP, et al. (2010) Toward discovery science of human brain function. Proc Natl Acad Sci U S A 107:4734-4739. CrossRef Medline

Buckner RL, Andrews-Hanna JR, Schacter DL (2008) The brain's default network: anatomy, function, and relevance to disease. Ann N Y Acad Sci 1124:1-38. CrossRef Medline

Chang L (2011) The role of stress on physiologic responses and clinical symptoms in irritable bowel syndrome. Gastroenterology 140:761-765. CrossRef Medline

Chang L, Lee OY, Naliboff B, Schmulson M, Mayer EA (2001) Sensation of bloating and visible abdominal distension in patients with irritable bowel syndrome. Am J Gastroenterol 96:3341-3347. CrossRef Medline

Chang LJ, Yarkoni T, Khaw MW, Sanfey AG (2013) Decoding the role of the insula in human cognition: functional parcellation and large-scale reverse inference. Cereb Cortex 23:739-749. CrossRef Medline

Craig AD (2009) How do you feel-now? The anterior insula and human awareness. Nat Rev Neurosci 10:59-70. CrossRef Medline

Daniels JK, McFarlane AC, Bluhm RL, Moores KA, Clark CR, Shaw ME, Williamson PC, Densmore M, Lanius RA (2010) Switching between executive and default mode networks in posttraumatic stress disorder: alterations in functional connectivity. J Psychiatry Neurosci 35:258-266. CrossRef Medline

Deen B, Pitskel NB, Pelphrey KA (2011) Three systems of insular functional connectivity identified with cluster analysis. Cereb Cortex 21:1498-1506. CrossRef Medline

Di X, Biswal BB (2014) Modulatory interactions between the default mode network and task positive networks in resting-state. Peer J 2:e367. CrossRef Medline

Dosenbach NU, Fair DA, Miezin FM, Cohen AL, Wenger KK, Dosenbach RA, Fox MD, Snyder AZ, Vincent JL, Raichle ME, Schlaggar BL, Petersen SE (2007) Distinct brain networks for adaptive and stable task control in humans. Proc Natl Acad Sci U S A 104:11073-11078. CrossRef Medline

Drossman DA (2006) The functional gastrointestinal disorders and the Rome III process. Gastroenterology 130:1377-1390. CrossRef Medline

Dunckley P, Aziz Q, Wise RG, Brooks J, Tracey I, Chang L (2007) Attentional modulation of visceral and somatic pain. Neurogastroenterol Motil 19:569-577. CrossRef Medline

Elsenbruch S, Rosenberger C, Enck P, Forsting M, Schedlowski M, Gizewski ER (2010) Affective disturbances modulate the neural processing of visceral pain stimuli in irritable bowel syndrome: an fMRI study. Gut 59: 489-495. CrossRef Medline

Etkin A, Egner T, Kalisch R (2011) Emotional processing in anterior cingulate and medial prefrontal cortex. Trends Cogn Sci 15:85-93. CrossRef Medline

Farb NA, Segal ZV, Anderson AK (2013) Attentional modulation of primary interoceptive and exteroceptive cortices. Cereb Cortex 23:114-126. CrossRef Medline

Filippi M, Valsasina P, Misci P, Falini A, Comi G, Rocca MA (2013) The organization of intrinsic brain activity differs between genders: a restingstate fMRI study in a large cohort of young healthy subjects. Hum Brain Mapp 34:1330-1343. CrossRef Medline

Fischl B, van der Kouwe A, Destrieux C, Halgren E, Ségonne F, Salat DH, Busa E, Seidman LJ, Goldstein J, Kennedy D, Caviness V, Makris N, Rosen B, Dale AM (2004) Automatically parcellating the human cerebral cortex. Cereb Cortex 14:11-22. CrossRef Medline

Fox MD, Snyder AZ, Vincent JL, Corbetta M, Van Essen DC, Raichle ME (2005) The human brain is intrinsically organized into dynamic, anticorrelated functional networks. Proc Natl Acad Sci U S A 102:9673-9678. CrossRef Medline

Friston KJ, Penny WD, Glaser DE (2005) Conjunction revisited. Neuroimage 25:661-667. CrossRef Medline

Grupe DW, Nitschke JB (2013) Uncertainty and anticipation in anxiety: an integrated neurobiological and psychological perspective. Nat Rev Neurosci 14:488-501. CrossRef Medline

Hall GB, Kamath MV, Collins S, Ganguli S, Spaziani R, Miranda KL, Bayati A, Bienenstock J (2010) Heightened central affective response to visceral sensations of pain and discomfort in IBS. Neurogastroenterol Motil 22: 276-e80. CrossRef Medline

Heft MW, Gracely RH, Dubner R, McGrath PA (1980) A validation model for verbal description scaling of human clinical pain. Pain 9:363-373. CrossRef Medline

Holtz K, Pané-Farré CA, Wendt J, Lotze M, Hamm AO (2012) Brain activation during anticipation of interoceptive threat. Neuroimage 61:857865. CrossRef Medline

Hong JY, Kilpatrick LA, Labus J, Gupta A, Jiang Z, Ashe-McNalley C, Stains J, Heendeniya N, Ebrat B, Smith S, Tillisch K, Naliboff B, Mayer EA (2013) Patients with chronic visceral pain show sex-related alterations in intrinsic oscillations of the resting brain. J Neurosci 33:11994-12002. CrossRef Medline

Ingalhalikar M, Smith A, Parker D, Satterthwaite TD, Elliott MA, Ruparel K, Hakonarson H, Gur RE, Gur RC, Verma R (2014) Sex differences in the structural connectome of the human brain. Proc Natl Acad Sci U S A 111:823-828. CrossRef Medline

Jiang Z, Dinov ID, Labus J, Shi Y, Zamanyan A, Gupta A, Ashe-McNalley C, Hong JY, Tillisch K, Toga AW, Mayer EA (2013) Sex-related differences of cortical thickness in patients with chronic abdominal pain. PLoS One 8:e73932. CrossRef Medline

Kong J, Spaeth RB, Wey HY, Cheetham A, Cook AH, Jensen K, Tan Y, Liu H, Wang D, Loggia ML, Napadow V, Smoller JW, Wasan AD, Gollub RL (2013) S1 is associated with chronic low back pain: a functional and structural MRI study. Mol Pain 9:43. CrossRef Medline

Kucyi A, Moayedi M, Weissman-Fogel I, Goldberg MB, Freeman BV, Tenenbaum HC, Davis KD (2014) Enhanced medial prefrontal-default mode network functional connectivity in chronic pain and its association with pain rumination. J Neurosci 34:3969-3975. CrossRef Medline

Kurth F, Zilles K, Fox PT, Laird AR, Eickhoff SB (2010) A link between the systems: functional differentiation and integration within the human in- 
sula revealed by meta-analysis. Brain Struct Funct 214:519-534. CrossRef Medline

Labus JS, Bolus R, Chang L, Wiklund I, Naesdal J, Mayer EA, Naliboff BD (2004) The visceral sensitivity index: development and validation of a gastrointestinal symptom-specific anxiety scale. Aliment Pharmacol Ther 20:89-97. CrossRef Medline

Labus JS, Mayer EA, Chang L, Bolus R, Naliboff BD (2007) The central role of gastrointestinal-specific anxiety in irritable bowel syndrome: further validation of the visceral sensitivity index. Psychosom Med 69:89-98. CrossRef Medline

Labus JS, Naliboff BN, Fallon J, Berman SM, Suyenobu B, Bueller JA, Mandelkern M, Mayer EA (2008) Sex differences in brain activity during aversive visceral stimulation and its expectation in patients with chronic abdominal pain: a network analysis. Neuroimage 41:1032-1043. CrossRef Medline

Labus JS, Gupta A, Coveleskie K, Tillisch K, Kilpatrick L, Jarcho J, Feier N, Bueller J, Stains J, Smith S, Suyenobu B, Naliboff B, Mayer EA (2013) Sex differences in emotion-related cognitive processes in irritable bowel syndrome and healthy control subjects. Pain 154:2088-2099. CrossRef Medline

Laird AR, Fox PM, Eickhoff SB, Turner JA, Ray KL, McKay DR, Glahn DC, Beckmann CF, Smith SM, Fox PT (2011) Behavioral interpretations of intrinsic connectivity networks. J Cogn Neurosci 23:4022-4037. CrossRef Medline

Leech R, Kamourieh S, Beckmann CF, Sharp DJ (2011) Fractionating the default mode network: distinct contributions of the ventral and dorsal posterior cingulate cortex to cognitive control. J Neurosci 31:3217-3224. CrossRef Medline

Loggia ML, Kim J, Gollub RL, Vangel MG, Kirsch I, Kong J, Wasan AD, Napadow V (2013) Default mode network connectivity encodes clinical pain: an arterial spin labeling study. Pain 154:24-33. CrossRef Medline

Lovero KL, Simmons AN, Aron JL, Paulus MP (2009) Anterior insular cortex anticipates impending stimulus significance. Neuroimage 45:976983. CrossRef Medline

Luders E, Toga AW (2010) Sex differences in brain anatomy. Prog Brain Res 186:3-12. CrossRef Medline

Lutz A, McFarlin DR, Perlman DM, Salomons TV, Davidson RJ (2013) Altered anterior insula activation during anticipation and experience of painful stimuli in expert meditators. Neuroimage 64:538-546. CrossRef Medline

Mainero C, Boshyan J, Hadjikhani N (2011) Altered functional magnetic resonance imaging resting-state connectivity in periaqueductal gray networks in migraine. Ann Neurol 70:838-845. CrossRef Medline

Manoliu A, Riedl V, Zherdin A, Mühlau M, Schwerthöffer D, Scherr M, Peters H, Zimmer C, Förstl H, Bäuml J, Wohlschläger AM, Sorg C (2014) Aberrant dependence of default mode/central executive network interactions on anterior insular salience network activity in schizophrenia. Schizophr Bull 40:428-437. CrossRef Medline

Mayer EA, Aziz Q, Coen S, Kern M, Labus JS, Lane R, Kuo B, Naliboff B, Tracey I (2009) Brain imaging approaches to the study of functional GI disorders: a Rome working team report. Neurogastroenterol Motil 21: 579-596. CrossRef Medline

Menon V (2011) Large-scale brain networks and psychopathology: a unifying triple network model. Trends Cogn Sci 15:483-506. CrossRef Medline

Menon V, Uddin LQ (2010) Saliency, switching, attention and control: a network model of insula function. Brain Struct Funct 214:655-667. CrossRef Medline

Moran LV, Tagamets MA, Sampath H, O’Donnell A, Stein EA, Kochunov P, Hong LE (2013) Disruption of anterior insula modulation of large-scale brain networks in schizophrenia. Biol Psychiatry 74:467-474. CrossRef Medline

Mykletun A, Stordal E, Dahl AA (2001) Hospital Anxiety and Depression (HAD) scale: factor structure, item analyses and internal consistency in a large population. Br J Psychiatry 179:540-544. CrossRef Medline
Naidich TP, Kang E, Fatterpekar GM, Delman BN, Gultekin SH, Wolfe D, Ortiz O, Yousry I, Weismann M, Yousry TA (2004) The insula: anatomic study and MR imaging display at 1.5 T. AJNR Am J Neuroradiol 25:222-232. Medline

Napadow V, LaCount L, Park K, As-Sanie S, Clauw DJ, Harris RE (2010) Intrinsic brain connectivity in fibromyalgia is associated with chronic pain intensity. Arthritis Rheum 62:2545-2555. CrossRef Medline

Popescu A, LeResche L, Truelove EL, Drangsholt MT (2010) Gender differences in pain modulation by diffuse noxious inhibitory controls: a systematic review. Pain 150:309-318. CrossRef Medline

Preuschoff K, Quartz SR, Bossaerts P (2008) Human insula activation reflects risk prediction errors as well as risk. J Neurosci 28:2745-2752. CrossRef Medline

Qiu E, Wang Y, Ma L, Tian L, Liu R, Dong Z, Xu X, Zou Z, Yu S (2013) Abnormal brain functional connectivity of the hypothalamus in cluster headaches. PLoS One 8:e57896. CrossRef Medline

Rapps N, van Oudenhove L, Enck P, Aziz Q (2008) Brain imaging of visceral functions in healthy volunteers and IBS patients. J Psychosom Res 64: 599-604. CrossRef Medline

Seeley WW, Menon V, Schatzberg AF, Keller J, Glover GH, Kenna H, Reiss AL, Greicius MD (2007) Dissociable intrinsic connectivity networks for salience processing and executive control. J Neurosci 27:2349-2356. CrossRef Medline

Sheehan DV, Lecrubier Y, Sheehan KH, Amorim P, Janavs J, Weiller E, Hergueta T, Baker R, Dunbar GC (1998) The Mini-International Neuropsychiatric Interview (M.I.N.I.): the development and validation of a structured diagnostic psychiatric interview for DSM-IV and ICD-10. J Clin Psychiatry 59 [Suppl 20]:22-33; quiz 34-57.

Song XW, Dong ZY, Long XY, Li SF, Zuo XN, Zhu CZ, He Y, Yan CG, Zang YF (2011) REST: a toolkit for resting-state functional magnetic resonance imaging data processing. PLoS One 6:e25031. CrossRef Medline

Spreng RN, Sepulcre J, Turner GR, Stevens WD, Schacter DL (2013) Intrinsic architecture underlying the relations among the default, dorsal attention, and frontoparietal control networks of the human brain. J Cogn Neurosci 25:74-86. CrossRef Medline

Sridharan D, Levitin DJ, Menon V (2008) A critical role for the right frontoinsular cortex in switching between central-executive and default-mode networks. Proc Natl Acad Sci U S A 105:12569-12574. CrossRef Medline

Straube T, Schmidt S, Weiss T, Mentzel HJ, Miltner WH (2009) Sex differences in brain activation to anticipated and experienced pain in the medial prefrontal cortex. Hum Brain Mapp 30:689-698. CrossRef Medline

Tillisch K, Mayer EA, Labus JS (2011) Quantitative meta-analysis identifies brain regions activated during rectal distension in irritable bowel syndrome. Gastroenterology 140:91-100. CrossRef Medline

Touroutoglou A, Hollenbeck M, Dickerson BC, Feldman Barrett L (2012) Dissociable large-scale networks anchored in the right anterior insula subserve affective experience and attention. Neuroimage 60:1947-1958. CrossRef Medline

Wang G, Erpelding N, Davis KD (2014) Sex differences in connectivity of the subgenual ACC. Pain 155:755-763. CrossRef Medline

Whitfield-Gabrieli S, Nieto-Castanon A (2012) Conn: a functional connectivity toolbox for correlated and anticorrelated brain networks. Brain Connect 2:125-141. CrossRef Medline

Wiech K, Tracey I (2013) Pain, decisions, and actions: a motivational perspective. Front Neurosci 7:46. CrossRef Medline

Woodward ND, Karbasforoushan H, Heckers S (2012) Thalamocortical dysconnectivity in schizophrenia. Am J Psychiatry 169:1092-1099. CrossRef Medline

Xue T, Yuan K, Zhao L, Yu D, Dong T, Cheng P, von Deneen KM, Qin W, Tian J (2012) Intrinsic brain network abnormalities in migraines without aura revealed in resting-state fMRI. PLoS One 7:e52927. CrossRef Medline 